\title{
AQUISIÇÃO DA LINGUAGEM ESCRITA A PARTIR DO GÊNERO DIÁRIO
}

\author{
Iana Maria Carvalho Alves* \\ Roberta Varginha Caiado ${ }^{* *}$ \\ Wanilda Maria Alves Cavalcanti ${ }^{* * *}$
}

RESUMO: No Brasil, a inclusão de crianças com desenvolvimento atípico circulando nas escolas, é uma realidade. No entanto, os sistemas educacionais que deveriam estar preparados para a recepção de tais alunos, nem sempre apresentam essa condição. Trazemos a inclusão educativa com a pretensão de apagar a ilusão de incapacidade, introduzindo a diversidade para esse ambiente, o que representa um desafio que deve ser enfrentado pelos sistemas gerais de ensino que precisam favorecer o acesso ao emprego de artifícios, adequados ao grupo, derivados do conhecimento sistemático. Propusemos o uso do gênero textual diário como uma fonte de letramento escolar a partir da produção escrita de dez crianças (típicas e atípicas) estudantes do $2^{\circ}$ ano do ensino fundamental, de uma escola particular da cidade do Recife. O objetivo desse artigo foi observar a eficácia das condições de produção oferecida pela professora, no momento da produção escrita dessas crianças, que facilitem o processo de alfabetização e letramento escolar dos alunos que mais precisam de apoio, além de perceber se esses conseguiram produzir a estrutura do gênero proposto. A base teórica que empregamos relaciona-se ao letramento, à teoria de gêneros, e à inclusão, fundamentando-se nos autores Marcuschi (2005), Bezerra (2017), Paiva (2019), Caiado (2017), Street (2014), Kleiman (1995), Mantoan (2001), Figueiredo (2008), Cavalcanti (2002). Metodologicamente, trabalharemos com a pesquisa qualitativa com o estudo de caso, como principal caminho para desenvolver este trabalho. Como resultado, mostramos o aspecto singular na trajetória da aprendizagem da escrita de cada uma das crianças e a importância do trabalho, a partir de gêneros textuais reais desde as séries iniciais. Esse estudo destaca o processo de alfabetização implicado no letramento, no ensino de língua a partir de gêneros textuais, na importância das características estruturais sobre o gênero promovendo a aprendizagem de todos e a inclusão dos alunos. Não observamos diferenças significativas entre as crianças típicas e atípicas pesquisadas no tocante à ortografia e ao gênero da linguagem diário. Muito pelo contrário, as crianças com transtornos demonstraram boa desenvoltura no desenvolvimento das ideias e os erros ortográficos encontrados são aqueles esperados para a idade e série. $O$ fato de a professora ter trabalhado de várias formas esse gênero (vídeos, com o próprio diário, livro didático, construção de páginas de diários pelas crianças) sugere uma boa compreensão e aplicação na vida concreta desses alunos (letramento).

PALAVRAS-CHAVE: Aquisição da Escrita; Ensino; Gênero Textual; Letramento; Inclusão

\footnotetext{
* Doutoranda em ciências da linguagem na Universidade Católica de Pernambuco (Unicap). Coordenadora pedagógica e fonoaudióloga do colégio Damas Recife.

** Doutora em Educação pela Universidade Federal de Pernambuco (UFPE).Pós-Doutorado em Linguística Aplicada pela UCPEL em 2016, supervisionado Prof. Dr. Vilson José Leffa. Professora da Universidade Católica de Pernambuco (Unicap).

*** Doutora em Salud y Familia pela Universidad de Deusto - Espanha. Fez estágio de Pós-doutorado na Universidade Federal da Paraíba (UFPB). Professora da Universidade Católica de Pernambuco (Unicap).
} 


\section{Introdução}

A temática da inclusão educacional é algo de grande relevância e importância na sociedade atual, pois além de ser um avanço para as minorias com transtornos e deficiências, é um pré-requisito na garantia da singularidade de todo e qualquer estudante, seja ele típico ou atípico.

Seguindo a trajetória de uma escola inclusivista, associamos os conceitos de letramento e gênero da linguagem considerando que são peças integrantes do processo de ensino-aprendizagem, bem como do processo de valorização da singularidade de cada aluno. Acreditamos que uma escola de qualidade é aquela, na qual o conteúdo formal e interação pela linguagem constituem o verdadeiro sentido da inclusão.

No presente artigo discorreremos acerca da inclusão educacional, do letramento escolar e dos gêneros da linguagem para respaldarmos as análises das produções textuais escritas de crianças de sete (07) anos, estudantes do $2^{\circ}$ ano do ensino fundamental de uma escola particular.

\section{Inclusão}

No Brasil, a inclusão de crianças com desenvolvimento atípico circulando nas escolas, é uma realidade. A inclusão e a exclusão começam na sala de aula, pois é através das experiências vivenciadas entre os alunos que se define a qualidade da participação deles no sistema de ensino-aprendizagem. Da mesma forma, são muito relevantes as relações entre os alunos e toda a comunidade educativa mais ampliada, já que a forma como cada escola promove a inclusão ou a exclusão é que vai definir a qualidade de aprendizagem e da vida escolar da criança.

Não se pode falar em inclusão e diversidade sem falar de identidade, pois é a nossa identidade que nos distingue dos demais. Como cada um é único, não cabe a distinção entre "gente normal" e "gente diferente". Todas as pessoas são diferentes entre si. Neste sentido, a escola precisa encarnar uma cultura pedagógica que ofereça oportunidade de atendimento adequado para todos, sem distinção de sexo, classe social, deficiência, etnia, etc... (CAVALCANTI, 2002)

Os sistemas educacionais inclusivos deveriam estar preparados para a recepção dos alunos com transtornos ou deficiências, embora, nem sempre apresentam essa condição. Nós acreditamos na inclusão educativa com a pretensão de apagar a ilusão de incapacidade, introduzindo a diversidade para esse ambiente, o que representa um desafio que deve ser 
enfrentado pelos sistemas gerais de ensino que precisam favorecer o acesso ao emprego de artifícios, adequados ao grupo, derivados do conhecimento sistemático.

Todo e qualquer aluno experimenta obstáculos e dificuldades em algum momento da sua trajetória escolar; essas dificuldades precisam ser superadas. As razões do fracasso escolar são várias e não devem ser encaradas apenas como culpa do aprendiz, mas também como uma inabilidade da escola para lidar com a singularidade do aluno e na promoção da inclusão. Ou seja, quando o aluno fracassa no aprendizado escolar, a escola fracassa no ensino de qualidade, também.

Para um ensino como esse, além dos conteúdos acadêmicos ministrados pelo professor, deve existir uma sensibilidade aguçada para considerar a subjetividade de cada aprendiz. Nessa via de mão dupla, a inclusão só ocorre com valores, princípios e atitudes claras e bem específicas de toda a comunidade escolar "A igualdade não está em desacordo com o respeito às diferenças entre as pessoas, antes o reforça" (MANTOAN, 2001, p. 56).

O professor é uma figura extremamente importante no processo de inclusão escolar, pois o seu olhar vai influenciar diretamente a sua prática pedagógica. Segundo Figueiredo (2019):

Para ser capaz de organizar situações de ensino e para ser capaz de gestar o espaço da sala de aula com o intuito de que todos os alunos possam ter acesso a todas as oportunidades educacionais e sociais oferecidas pela instituição escolar, este professor deve ter consciência de que o ensino tradicional deverá ser substituído por uma pedagogia de atenção à diversidade. (FIGUEIREDO, 2019, p.142)

Dentro do processo de socialização no ambiente educacional, fatores ligados ao bom desenvolvimento do ensino-aprendizagem devem ser levados em consideração, e dentre eles podemos citar: a apropriação da leitura e da escrita, os conhecimentos linguísticos e matemáticos e os demais letramentos escolares. Passaremos para uma breve discussão sobre letramento.

\section{Letramento}

Mais importante do que localizar as consequências sociais universais do letramento, é compreender como cada sociedade elabora seu modo de vida e interação a partir dele, já que cada membro de uma sociedade participa da construção do sistema letrado da sua comunidade independentemente de saber ler ou escrever (BAZERMAN, 2007).

O aspecto da interação social é tão importante para o funcionamento da língua que não se pode falar em um único letramento, mas sim de múltiplos letramentos ou práticas de letramentos, cuja motivação e consequências se especificam apenas no contexto (STREET, 2014). 
Sobre o letramento escolar, Kleiman (1995) afirma que esta importante agência de letramento, a escola, não prioriza esta atividade como prática social, mas apenas com um único tipo de letramento: a alfabetização e o processo de aquisição de códigos. Esta conduta além de gerar um possível preconceito linguístico, pode gerar algo ainda mais grave que é a divisão de uma mesma espécie humana em duas subespécies cognitivamente distintas: os que sabem ler e escrever e os que não sabem.

O grande desafio da escola com base inclusiva é o de possibilitar o desabrochar dos múltiplos letramentos de cada aluno, levando em consideração sua singularidade e peculiaridade, não importando sua condição física, intelectual ou social.

Sabemos que a escola é uma agência de letramento e o ensino da língua portuguesa com base em gêneros o mais adequado, pois estes apresentam características compartilhadas socialmente que facilitam o processo de interação do sujeito na linguagem. A seguir discorreremos sobre o conceito de gêneros da linguagem.

\section{Gêneros da linguagem}

Marcuschi (2005) aponta os gêneros textuais como entidades sociodiscursivas e formas de ação social incontornáveis de qualquer situação comunicativa. Assim, os gêneros surgem como formas da comunicação, atendendo a necessidades de expressão do ser humano, moldados sob influência do contexto histórico e social das diversas esferas da comunicação humana.

Segundo Bezerra, a designação para os gêneros, atualmente no Brasil, polariza-se em discursivo/textual, mas o autor afirma que os gêneros são, simultaneamente e indissociáveis do discurso e do texto e, ainda, acrescenta que seria um equívoco reduzi-lo a qualquer um desses polos (BEZERRA, 2017).

Apesar de o gênero ser descrito como tipos relativamente estáveis de enunciados, eles podem sofrer mudanças criativas de acordo com o contexto. Essas ações de linguagem não recorrentes são objeto de estudo da teoria da complexidade. A teoria da complexidade pode ser definida como o caos, um comportamento imprevisível de um sistema determinístico; ou seja, o aparecimento da irregularidade no meio de uma suposta regularidade. Eventualmente surgem novos comportamentos linguísticos em gêneros bem estabilizados, configurando assim mais um aspecto dinâmico da linguagem. Portanto, os gêneros estão cada vez mais multimodais, imprevisíveis e dinâmicos.

Nesta perspectiva de gêneros como dinâmicos podemos fazer um link com a teoria da complexidade. Nas palavras de Barros e Caiado (2017, p.249) temos: "Entendemos por 
Teoria da Complexidade o estudo dos sistemas complexos que são dinâmicos e não seguem caminhos lineares e incorporam, dentro de uma determinada área do conhecimento, várias disciplinas interligadas".

O gênero da linguagem é, portanto, dinâmico, mas é também multimodal. A experiência multimodal é uma forte característica da dinamicidade da linguagem, pois através das múltiplas semioses, com a junção de textos linguísticos, imagéticos, dentre outros, abre-se à possibilidade de inúmeras experiências que fogem da estabilidade da mesma (linguagem).

Ao optar por gêneros da linguagem sem focar, exclusivamente no texto oral, escrito ou gestual, está sendo privilegiada a experiência humana com a linguagem em geral, independentemente do(s) modo(s) semiótico(s) (OLIVEIRA; PAIVA, 2019).

A partir do exposto, podemos constatar que a linguagem é dinâmica, porque considera a interação, a cognição, a cultura e demais elementos que se apresentem no processo de aprendizagem da mesma. Ao enxergar a linguagem como dinâmica conferem espaço à singularidade do sujeito, que apresenta uma experiência única e criativa com ela.

Passaremos agora para a análise do gênero da linguagem diário, que revela aspectos mais formais que caracterizam tal gênero como: data, saudação inicial, saudação final; como outros aspectos imprevisíveis que surgem no desenvolvimento do texto de cada aluno com toda a sua criatividade de sujeito escritor de sua língua.

\section{Aspectos metodológicos}

A presente pesquisa caracteriza-se por ser qualitativa, transversal e descritiva. Como corpus da pesquisa, utilizamos textos escritos de 10 (dez) crianças, estudantes do $2^{\circ}$ ano do ensino fundamental de uma escola particular da cidade do Recife sendo 5 (cinco) crianças típicas e 5 (cinco) crianças atípicas. Aqui chamamos de atípicas as crianças com diagnóstico de algum transtorno ou deficiência e de crianças típicas as crianças que não possuem tal especificidade. Cada aluno será identificado por um número seguido da letra “T” para Típico e a letra "A" para Atípico. Os textos escritos analisados fizeram parte da culminância do trabalho com o gênero diário, na disciplina de língua portuguesa. Acreditamos que a escrita a partir de gêneros reais motiva e colabora no processo de aquisição da linguagem e do letramento escolar.

O gênero diário foi trabalhado de diversas formas pela professora: com demonstração do seu próprio diário, slides e pequenos vídeos sobre a confecção de um diário, escrita dos próprios alunos com os itens considerados fundamentais para caracterizar esse gênero. 
Durante o trabalho que durou cerca de um (1) mês, em média, os alunos eram levados a reconhecer características essências desse gênero, a partir das pistas dadas pela professora, como: data, vocativo, desenvolvimento, despedida e assinatura (características formais do gênero); e a funcionalidade da escrita de um diário como expressão de sentimentos, como uma escrita íntima, de relato do dia.

\section{Analisando o gênero diário:}

A seguir apresentamos os textos das crianças que fizeram parte da pesquisa, bem como a análise dos dados coletados. O nome das crianças foi retirado da atividade para preservar o sigilo, elas serão identificadas por códigos que vão de 1 até 10 seguidos pelas letras " $T$ " para indicar típica e " $\mathrm{A}$ " para indicar atípica.

Aluna 1T:

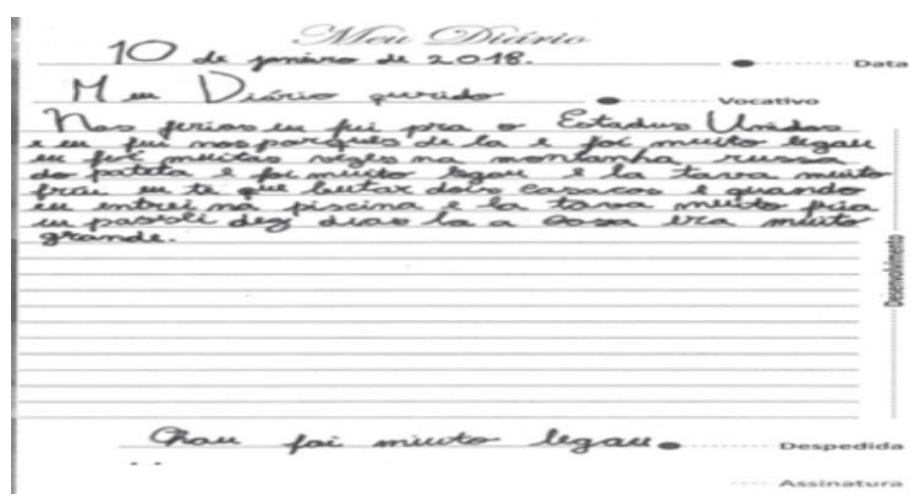

10 de janeiro de 2018

Meu Diário querido

Nas férias en fui para os Estados Unidos e eu fui nos parques de la e foi muito legan eu fui muitas vezes na montanha russa do pateta e foi muito legau e lá tava muito frio eu ter que butar dois casacos e quando eu entrei na piscina e lá tava muito frio eu passei dez dias lá a casa era muito grande. Chan foi muito legau.

A aluna 1T, Típica, em relação aos aspectos do gênero, apresentou a saudação inicial (vocativo); no desenvolvimento relatou um acontecimento muito significativo para ela que foi sua viagem aos parques dos Estados Unidos; para finalizar, apresentou despedida e assinatura. No tocante a aquisição da linguagem escrita esta aluna encontra-se alfabetizada com a presença de alguns fenômenos linguísticos na sua ortografia, tais como: omissão de letras, falta de acento gráfico, transcrição de fala. Podemos perceber que 1T entendeu a funcionalidade e estrutura do gênero diário e que apresenta alguns “erros"oufenômenos linguísticos na sua escrita. Corroborando com Street (2014) ao afirmar que existem múltiplos letramentos. 
Aqui percebemos que a aluna já se apropriou tanto da estrutura do gênero diário como de sua funcionalidade (um tipo de letramento), mas se encontra em processo de letramento do aspecto ortográfico da linguagem escrita (fato que está dentro do esperado para a série e idade).

Aluno $2 \mathrm{~T}$ :

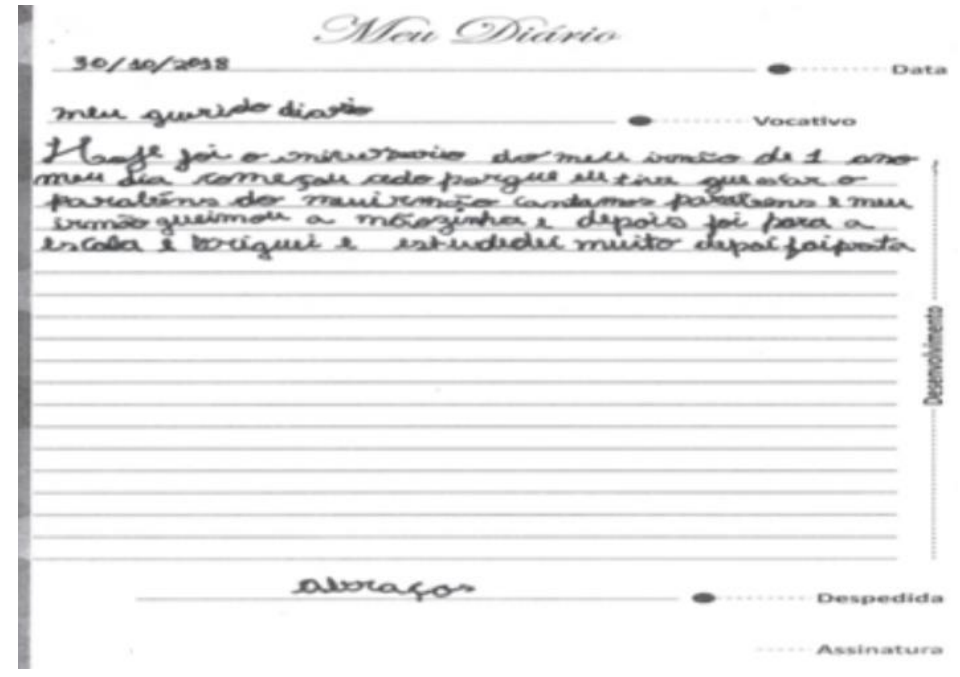

$30 / 10 / 2018$

Meu querido diário

Hoje foi o aniversario do meu irmão de 1 ano

Meu dia comecou cedo porque ele teve que cantar o parabéns do menirmão cantamos parabéns e meu irmão queimou a mãozinha e depois foi para escola e briguei e estudedei muito depoifoiprata

Abraços

$\mathrm{O}$ aluno $2 \mathrm{~T}$, nos aspectos referentes ao gênero que estamos tratando, apresentou a saudação inicial (vocativo); no desenvolvimento relatou um acontecimento bem marcante para ele, que foi o aniversário do irmão e o fato deste ter queimado a mão; para finalizar, apresentou despedida e assinatura.

Apresentou os seguintes fenômenos linguísticos na escrita: acentuação gráfica indevida, plural dos nomes indevidos, pontuação indevida, representação múltiplas de letras com sonoridade parecidas, omissão de letras, acréscimo de letras; apresentou boa caligrafia.

Verificamos que 2T utilizou o diário como um verdadeiro confidente, contando algo muito importante e ao mesmo tempo preocupante para ele (o irmãozinho que queimou a mão). Este caso expressa bem a afirmação de Bezerra (2017) ao constatar que o gênero é indissociável tanto do discurso quanto do texto. Em relação aos fenômenos linguísticos encontrados na escrita do aluno, constatamos que nenhum deles está fora do esperado para a série escolar cursada por ele.

Aluno 3T: 


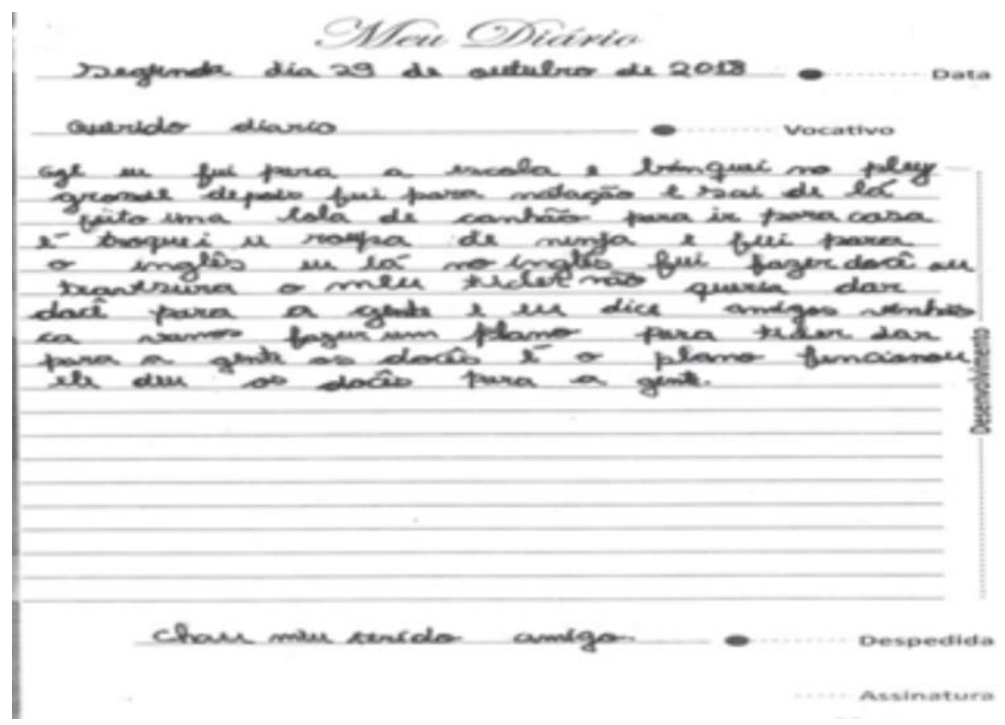

Segunda dia 29 de outubro de 2018

Querido diário

Oge eu fui para escola e brinquei no play gronde depois fui para natação e sai de lá feito uma bala de canhão para ir para casa é troquei u roupa de ninja e fui para travessura o meu ticher não queria dar doce para a gente e eu dice amigos venhão Ca vamos fazer um plano para ticher dar para a gente os doces é o plano funcionou ele deu os doces para a gente.

Chau meu querido amigo.

O aluno 3T, nos aspectos referentes ao gênero, apresentou a saudação inicial (vocativo); no desenvolvimento relatou um acontecimento significativo que foi uma atividade lúdica no curso de inglês; para finalizar, apresentou despedida e assinatura. Analisando a escrita ortográfica de 3T encontramos os seguintes fenômenos linguísticos: acentuação gráfica indevida, representação múltipla de letras com sonoridade parecidas, troca de letras, uso indevido de maiúsculas e minúsculas; apresentou boa caligrafia.

Quando este aluno traz um diálogo e até mesmo uma certa fantasia para o seu diário, ele se apropria da estrutura do gênero, porém traz também aspectos dinâmicos e imprevisíveis, assim como afirma Paiva (2019). Nessa dinamicidade da linguagem cabe a criatividade de cada sujeito inserido nela.

Aluno 4T:

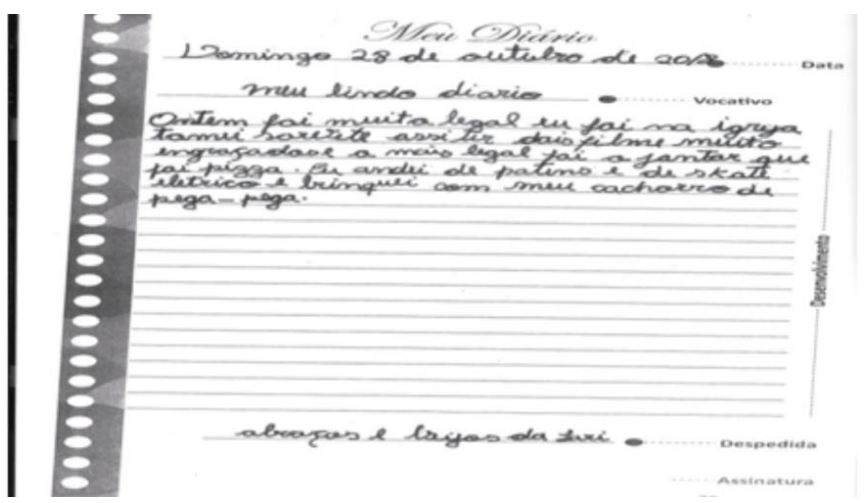




\section{Domingo 28 de outubro de 2018}

Meu lindo diário

Ontem foi muito legal eu foi na igreja tomei sorvete assistir dois filme muito engraçados e a mais legal foi o jantar que foi pizza. Eu andei de patins e de skate elétrico e brinquei com meu cachorro de pega-pega.

Abraços e beijos

O aluno 4T, típico, apresentou os elementos essenciais da estruturação do gênero diário com a saudação inicial (vocativo); no desenvolvimento relatou um dia do seu final de semana dando ênfase a ida à igreja, assistir filmes, comer pizza, brincar com o seu cachorro; para finalizar, apresentou despedida e assinatura.

Nos aspectos da aquisição da ortografia apresentou os fenômenos linguísticos: dificuldades de acentuação gráfica, hipercorreção; apresentou uma caligrafia muito boa. Neste caso específico fica evidente a importância de cada membro da sociedade na construção do sistema letrado da sua comunidade. (BAZERMAN, 2007)

O presente aluno além de compreender a estruturação do gênero diário, apresenta também grande desenvoltura nos aspectos ortográficos da língua escrita, pois os fenômenos linguísticos apresentados aqui são característicos de alunos de séries superiores.

Aluno 5T :

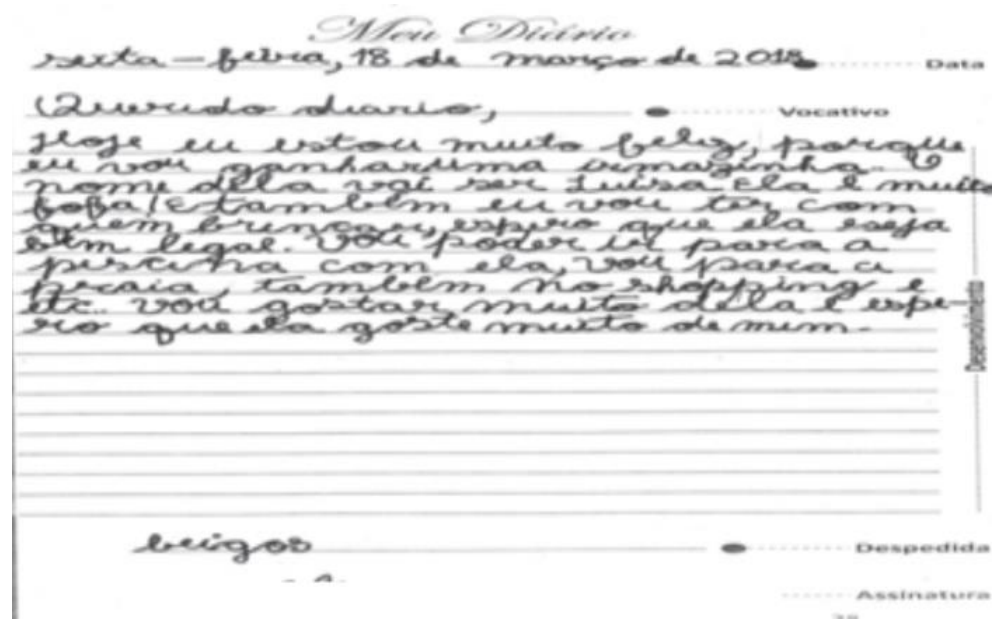

Sexta-feira, 18 de março de 2018

Querido diario,

Hoje en estou muito feliz, porque en vou ganhar uma irmazinha. O nome dela vai ser Luiza Ela e muito fofa, E também eu vou ter com quem brincar,espero que ela seja bem legal. Você poder ir para a piscina com ela, vou para a praia também no shopping e etc. Vou gostar muito dela e espero que ela goste muito de mim. beigos

O aluno 5T, típico apresentou as seguintes características na produção do gênero diário: saudação inicial (vocativo); no desenvolvimento relatou um acontecimento muito significativo em sua vida, que foi o nascimento da irmã e suas expectativas em torno desse evento; para finalizar, apresentou despedida e assinatura. 
$\mathrm{Na}$ escrita ortográfica apresentou os fenômenos linguísticos: dificuldade de acentuação gráfica, junção indevida de palavras, representação múltipla de letras com sonoridade parecidas; apresentou caligrafia boa. De acordo com Caiado (2017) a linguagem, enquanto sistema complexo, não segue caminhos lineares. Aqui $5 \mathrm{~T}$ se utilizou do diário para traçar o caminho de relato dos seus sentimentos mais profundos, que era a chegada de uma irmãzinha com todas as expectativas, fantasias e sonhos de uma criança de 7 anos.

Aluno 6A:

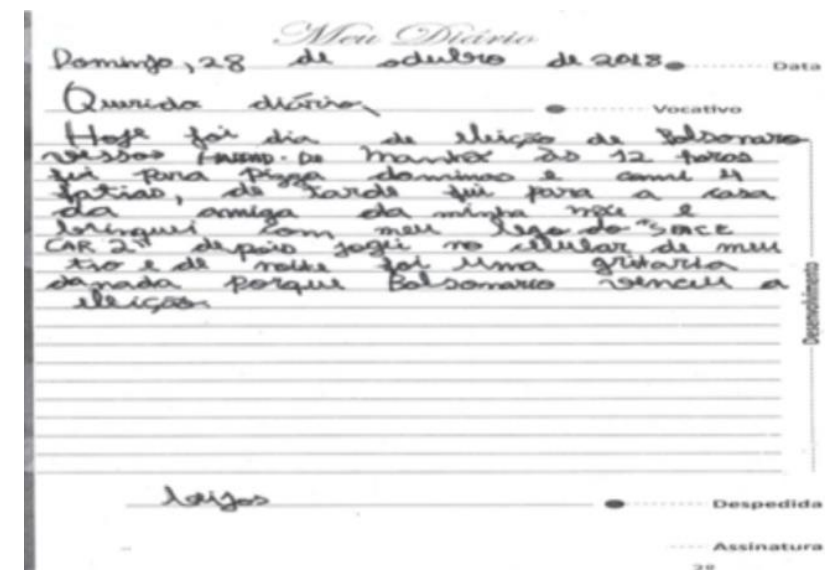

Domingo, 28 de outubro de 2018

Querido diário,

Hoje foi dia de eleição de Bolsonaro vessos Haddad. De manhã às 12 horas fui pizza dominós e comi 4 fatias, de tarde fui para a casa da amiga da minha mãe e brinquei com meu lego do 'SPACE CAR 2" depois jogei no celular de meu tio e de noite foi uma gritaria porque Bolsonaro venceu a eleições beijos

O aluno 6A, atípico com transtorno psiquiátrico. O laudo com o diagnóstico de transtorno psiquiátrico, foi entregue pelos pais e elaborado por um psiquiatra. Ele apresentou no tocante à estrutura do gênero a saudação inicial (vocativo); no desenvolvimento relatou um acontecimento muito significativo para todo o país que foi a eleição presidencial com muito barulho nas comemorações pelo vencedor, suas brincadeiras naquele dia, o fato de ter comido pizza; para finalizar, apresentou despedida e assinatura.

No aspecto ortográfico apresentou os fenômenos linguísticos: representação múltipla de letras com sonoridade parecidas; apresentou caligrafia regular. Quando partimos do pressuposto que cada um é único, não se pode falar em gente normal e gente diferente (Cavalcanti, 2002); percebemos que o fato de uma criança ter um transtorno psiquiátrico não implica necessariamente que esta não atinja o letramento escolar. Muito pelo contrário, neste caso 6A atingiu perfeitamente as metas referentes à apropriação do gênero em questão, assim também ocorreu no tocante a ortografia (tendo em vista um aluno do $2^{\circ}$ ano do ensino fundamental). 
Aluno 7A:

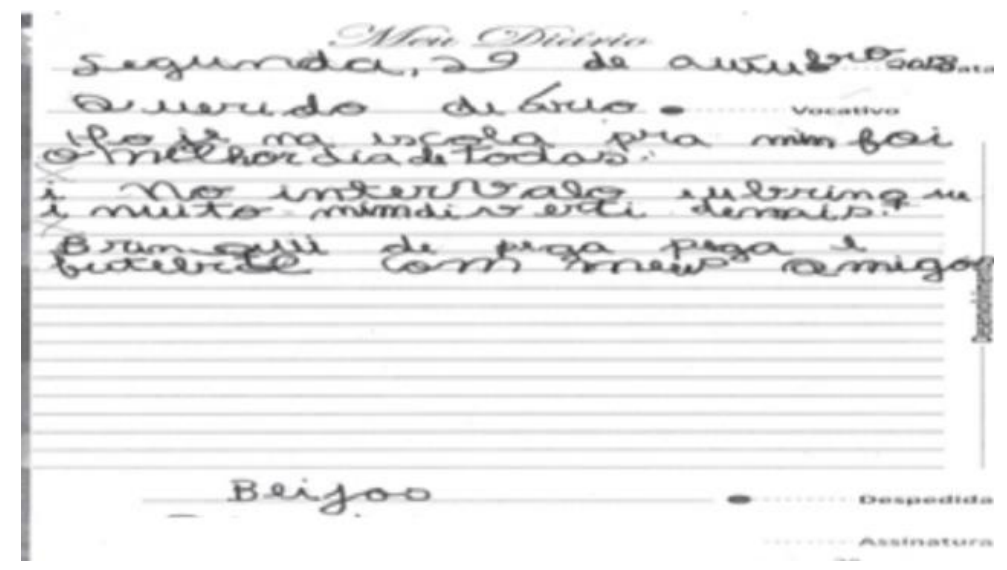

Segunda, 29 de outubro de 2018

Querido diário

Hoje na escola pra mim foi o melhor dia de todas.

$i$ No intervalo eu brinque

i muito mimdiverti demais.

Brinquei de pega pega e

bitebite com meus amigos

Beijos

O aluno 7A, atípico com TDAH (Transtorno do Déficit de Atenção e Hiperatividade) e TOD (Transtorno Opositor). O diagnóstico de TDAH e de T.O. foi fornecido pelos pais e elaborado por um médico neurologista. Apresentou os seguintes aspectos de estruturação do gênero diário: saudação inicial (vocativo); no desenvolvimento relatou o seu dia na escola, com a sua alegria de ter brincado com os colegas no recreio, fato que não é tão comum pelo temperamento mais intempestivo do aluno; para finalizar, apresentou despedida e assinatura.

$\mathrm{Na}$ construção da ortografia apresentou fenômenos linguísticos do tipo: transcrição de fala, separação indevida; apresentou grafia diferenciada em alguns momentos. Apesar da sua grafia um tanto irregular para um $2^{\circ}$ ano, esse aluno apresentou grande crescimento se comparado ao início do ano letivo, no qual se recusava a escrever na letra cursiva e a participar das aulas de língua portuguesa alegando ser algo chato e cansativo.

Aqui podemos evidenciar o trabalho de conquista diária feito pela professora, que corrobora com os postulados de Figueiredo (2019) que afirma que o professor deve ter a consciência de que o ensino tradicional deverá ser substituído por uma pedagogia de atenção à diversidade. 
Aluno 8A:

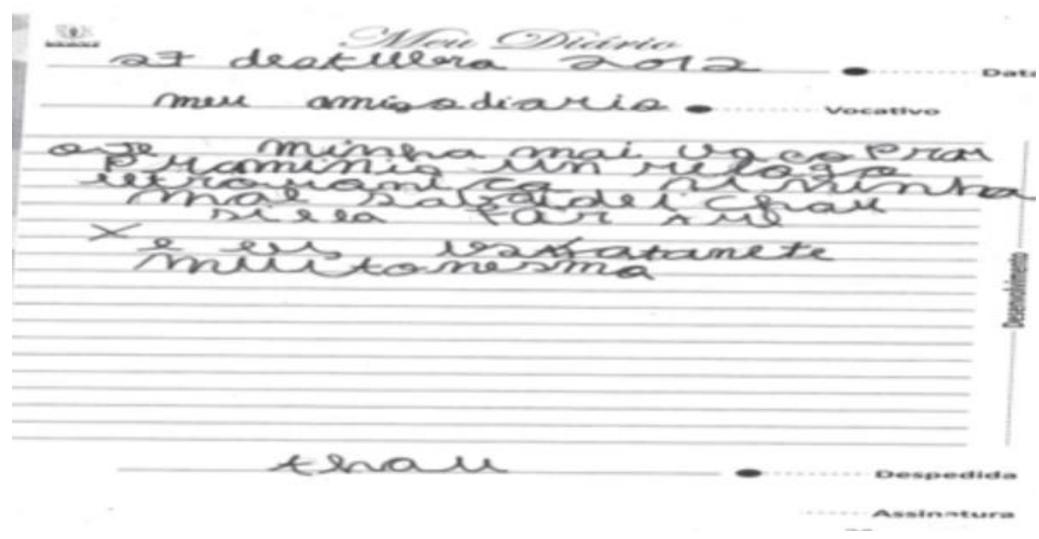

27 deotubro 2012

Oje minha mai as eo pra

caminia um relogo

eletrônico i ninha

mãesabaide i chan

si e La far que

eeusesatamete

muitonesmo

than

O aluno 8A, atípico com TDAH, discalculia e dislexia. O diagnóstico de TDAH, Discalculia e Dislexia trazido pelos pais foi fornecido pelo médico neurologista. Em relação ao gênero diário apresentou a saudação inicial (vocativo); no desenvolvimento relatou um acontecimento muito significativo para ele que foi a compra de um relógio eletrônico, contudo em alguns trechos não deu para entender algumas palavras e ideias; para finalizar, apresentou despedida e assinatura.

$\mathrm{Na}$ aquisição da linguagem escrita apresentou os seguintes fenômenos linguísticos: omissão de letras, dificuldade de acentuação gráfica, dificuldade de pontuação, transcrição de fala, junção e separação indevida de palavras, palavras ininteligíveis; apresentou certa irregularidade na caligrafia.

A partir desse exemplo verificamos que o presente aluno apresenta uma dificuldade acentuada na escrita padrão das palavras, justificada pela dislexia, mas que conseguiu atingir a proposta do gênero diário muito bem. Dessa forma validamos a afirmação de Marcuschi (2005) de que os gêneros surgem como formas de comunicação sendo moldados pelo contexto histórico e social das diversas esferas da comunicação humana. Portanto, $8 \mathrm{~A}$ mesmo apresentando uma certa dificuldade na legibilidade de algumas palavras conseguiu se expressar através da esfera comunicativa específica com o gênero diário. 
Aluna 9A:

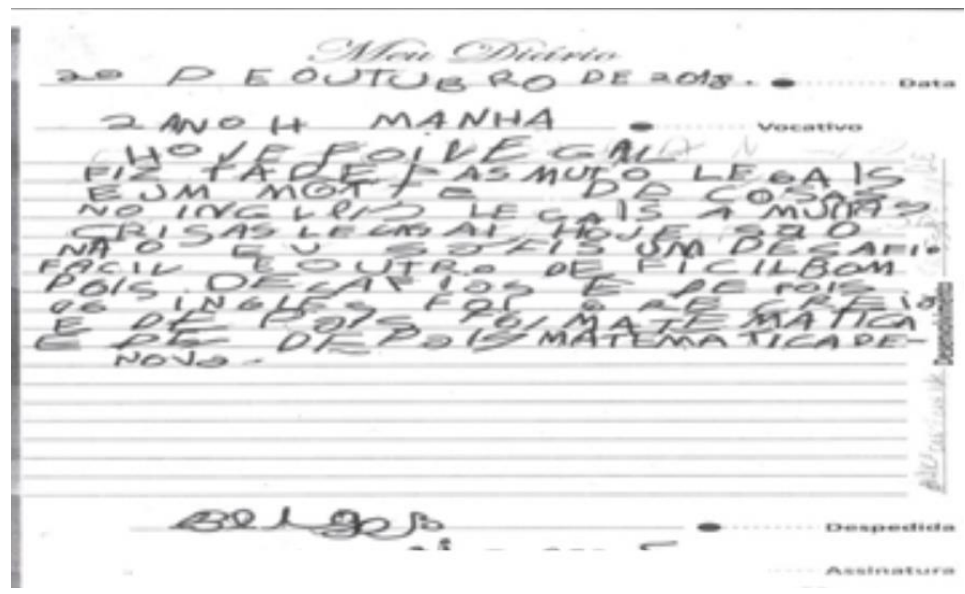

20 DE OUTUBRO DE 2018
2 ANO H MANHA
HOJE FOI LEGAL
FIZ TAREFAS MUITO LEGAIS
E UM MOTE DE COISAS
NO INGLES LEGAIS A MUITAS
COIS AS LEGAIS HOJE SAO
NÃO EU SO FIS UM DESAFIO
E OUTRO DIFICIL BOM
POIS DESAFIOS E DEPOIS
DE INGLES FOI O RECREIO
E DEPOIS FOI MATEMATICA
E DE DEPOIS MATEMATICA DE NOVO
BeijOS

A aluna 9A, atípica com TEA (Transtorno do Espectro Autista). O diagnóstico de TEA trazido pelos pais foi elaborado por um médico psiquiatra. No tocante a parte estrutural do gênero proposto ela não apresentou a saudação inicial (vocativo) colocou a série e a letra da sua turma; no desenvolvimento do texto relatou o seu dia na escola, o que é muito habitual no trabalho com autistas na escola: relatar a rotina e a previsibilidade das tarefas do dia; para finalizar, apresentou despedida e assinatura.

No aspecto da escrita ortográfica apresentou os seguintes fenômenos linguísticos: omissão de letras, acréscimo de letras, acentuação gráfica indevida, hipercorreção, repetição de palavras; letra bastão em toda a extensão do texto com exceção da despedida, que fez na cursiva.

A letra cursiva é um dos objetivos a serem alcançados no $2^{\circ}$ ano do ensino fundamental. Um aspecto bem peculiar na escrita de 9A foi a escrita "2 ANO H MANHÃ" ao invés da saudação inicial, o que nos sugere ser decorrente da prática diária das crianças de escrever esse conteúdo nos cadernos escolares diariamente, e o fato da necessidade de rotina repetitiva e previsibilidade dos sujeitos autistas. Outra reflexão que cabe aqui é a visão de escola como 
importante agência de letramento, mas que algumas vezes não prioriza esta atividade como prática social e sim se detém num único letramento: o processo de alfabetização e aquisição de códigos. (KLAIMAN, 1995)

Aluno 10A:

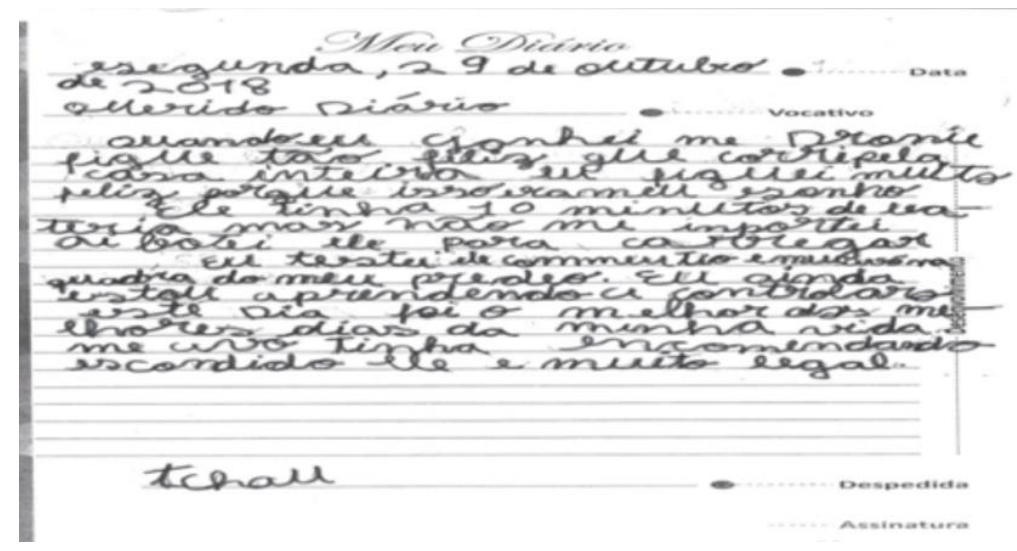

segunda, 29 de outubro

Querido diário

Quando eu ganhei meDronie

Figue tão feliz que corri pela

Casa inteira eu figuei muito

Felizporque isso erameu sonbo

Ele tinha 10 minutos de bateria

mas não me importei

Eu testei elecommentio e menavo na

Quadra do men predeo. Eu ainda

estou aprendendo a controlaro

este dia foi o melhor dos melhores

dias da minha vida

mi avo tinha encomendado

escondido ele e muito legal

tchan

O aluno 10A, atípico, com TDAH. O laudo de TDAH foi apresentado pela família e elaborado pelo médico neurologista. Nos aspectos referentes ao gênero proposto o aluno apresentou a saudação inicial (vocativo); no desenvolvimento relatou um acontecimento muito significativo na vida dele, que foi ser presenteado com um drone pelo seu avô que ele tanto ama; para finalizar, apresentou despedida e assinatura.

No tocante à ortografia apresentou os fenômenos linguísticos do tipo: omissão de letras, junção indevida de palavras, uso indevido de acentuação gráfica; apresentou caligrafia regular. 10A foi um aluno que apresentou muita resistência na socialização com os colegas e professora, além de grande agitação e indisciplina em sala de aula; fato que o atrapalhava bastante no cumprimento das atividades escolares. A professora, em conjunto com a equipe psicopedagógica, chamou a família para uma parceria e solicitou uma avaliação de profissionais clínicos como psicólogo, psicopedagogo, fonoaudiólogo e neurologista para 
compreender melhor o comportamento diferenciado do aluno, que não facilitava seu progresso educacional. A família firmou parceria com a escola, realizou todas as avaliações e acompanhamentos solicitados até chegar ao laudo de TDAH e as providências médicas e terapêuticas necessárias foram tomadas.

Com o trabalho especializado dentro e fora da escola, em conjunto com a família, percebemos que $10 \mathrm{~A}$ se descobriu em algumas potencialidades entre elas na leitura e matemática, e que muitos daqueles comportamentos indesejados foram minimizados. Portanto, a igualdade não está em desacordo com o respeito às diferenças entre as pessoas, antes o reforça. (MANTOAN, 2001)

A partir dos 10 textos analisados acima verificamos a riqueza da escrita das crianças baseada no ensino atrelado ao gênero da linguagem diário, possibilitando o letramento escolar do conteúdo proposto e a inclusão de fato, pois cada aluno apresentou as características estáveis do gênero proposto sem, contudo, perder a sua criatividade.

\section{Considerações finais}

A presente pesquisa teve como objetivos observar a eficácia das condições de produção oferecida pela professora, no momento da produção escrita das crianças, que facilitem o processo de alfabetização e letramento escolar; e se estas crianças conseguiram produzir a estrutura do gênero proposto. Tudo isso com um olhar bem particularizado para os alunos atípicos.

Podemos constatar que dos 10 (dez) alunos pesquisados, 9 (nove) apresentaram as 4 características do gênero propostas pela professora (data, vocativo, desenvolvimento, despedida e assinatura). Apenas 1(uma) aluna (com TEA) não apresentou o vocativo, porém apresentou as demais características esperadas para o gênero.

Também pudemos verificar que todas as crianças participantes da pesquisa estão alfabetizadas, na fase de aquisição da ortografia padrão de escrita e não houve diferenças significativas no letramento da escrita tendo como referência crianças do $2^{\circ}$ ano do ensino fundamental.

No tocante aos letramentos analisados, tanto do gênero diário, quanto da aquisição da linguagem escrita, observamos que as 10 crianças não estão tão diferentes de um contexto escolar de início de ensino fundamental, porém conseguimos encontrar as singularidades próprias de cada uma delas dentro de uma suposta homogeneidade da mesma sala de aula.

Não observamos diferenças significativas entre as crianças típicas e atípicas pesquisadas no tocante à ortografia e ao gênero da linguagem diário. Muito pelo contrário, as crianças 
com transtornos demonstraram boa desenvoltura no desenvolvimento das ideias e os erros ortográficos encontrados são aqueles esperados para a idade e série.

$\mathrm{O}$ fato de a professora ter trabalhado de várias formas esse gênero (vídeos, com o próprio diário, livro didático, construção de páginas de diários pelas crianças) sugere uma boa compreensão e aplicação na vida concreta desses alunos (letramento). Os alunos de maneira geral parecem ter compreendido muito bem o uso social do gênero proposto e a professora demonstrou bastante sensibilidade e perspicácia ao optar pela construção do conhecimento dos alunos de maneira interativa e autônoma.

Vale salientar aqui a atuação dessa professora como alguém que não subestimou em nenhum momento o potencial dos seus alunos, não poupando esforços para que "todos" os alunos da sua sala de aula compreendessem profundamente a instância social diário, fazendo isso de maneira muito lúdica, leve, sem pressa.

Durante aproximadamente 1 mês esses alunos tiveram a oportunidade de ouvir, trocar ideias, olhar os textos uns dos outros, dar sugestões para melhorar o texto do colega tanto relativo ao gênero quanto a ortografia das palavras. Ou seja, os nossos resultados apontam para uma maior harmonia e letramento do gênero proposto a partir do momento em que essas crianças se tornam partícipes ativos do contexto de sala de aula.

Podemos afirmar, no caso aqui estudado, que as diferenças entre alunos típicos e atípicos foram inexistentes e que a postura inclusiva da professora, bem como seu domínio teórico acerca dos gêneros de linguagem e aquisição da linguagem escrita facilitaram sobremaneira esse excelente resultado.

\title{
ACQUISITION OF THE WRITTEN LANGUAGE FROM THE DAILY GENDER
}

\begin{abstract}
In Brazil, the inclusion of children with atypical development circulating in schools is a reality. However, the educational systems that should be prepared for the reception of such students, do not always present this condition. We bring educational inclusion with the intention of erasing the illusion of incapacity, introducing diversity to this environment, which represents a challenge that must be faced by general education systems that need to favor access to the use of tools, suitable for the group, derived from systematic knowledge. We proposed the use of the daily textual genre as a source of school literacy based on the written production of ten (10) children (typical and atypical) students of the 2nd year of elementary school, from a private school in the city of Recife. The objective of this research was to observe the effectiveness of the production conditions offered by the teacher, at the time of the written production of these children, which facilitate the process of literacy and school literacy of the students who most need support, in addition to realizing if they were able reproduce the structure of the proposed genre. The theoretical basis we used was based on authors who work with textual genres, with literacy and inclusion: Marcuschi, Bezerra, MenezesPaiva, Caiado, Street, Kleiman, Mantoan, Figueiredo, Cavalcanti. We adopted qualitative research as the main way to develop this work. As results we show the singular aspect in the trajectory of the learning of the writing of each one of the children and the importance of the work from real and specific textual genres since the initial series. This study highlights the literacy process involved in literacy, in the teaching of language based on textual genres, in the importance of structural characteristics about gender, promoting everyone's learning and the inclusion of students. We did not observe significant differences between the typical and atypical children surveyed with regard to the spelling and gender of the daily language. Quite the contrary, children with disorders have demonstrated good
\end{abstract}


resourcefulness in the development of ideas and the spelling errors found are those expected for their age and grade. The fact that the teacher worked in this genre in various ways (videos, with her own diary, textbook, construction of diary pages by the children) suggests a good understanding and application in the concrete life of these students (literacy).

KEYWORDS: Acquisition of Writing; Inclusion; Textual Gender; Text; Teaching.

\section{REFERÊNCIAS}

BAZERMAN, Charles. Escrita, gênero e interação social. São Paulo: Cortez, 2007.

BARROS, F. R. A. R.; CAIADO, R. V. R. Lingua portuguesa na web 3.0: relações complexas de ensino por meio dos recursos educacionais abertos (REAS). Porto Alegre: revista Entremeios, vol. 15, jul/dez 2017.

BEZERRA, B. Gêneros no contexto brasileiro: questões [meta]teóricas e conceituais. São Paulo: Parábola, 2017.

CAVALCANTI, W.M.A. Diversidade X escola: um problema que não se reconhece como tal. Recife: Revista Educação teorias e práticas, ano2, nº 2, 2002.

FIGUEIREDO, R. V. A formação de professores para inclusão dos alunos no espaço pedagógico da diversidade. In: Maria Tereza Eglér Mantoan. (Org.). O desafio das diferenças nas escolas.1 ed. Petrópolis: Vozes, 2008, v. 1, p. 141-145.

KLEIMAN, ÂNGELA B. Os significados do letramento: uma nova perspectiva sobre a prática social da escrita. Campinas/SP: Mercado de Letras, 1995.

MARCUSCHI, L. A. Gêneros textuais: definição e funcionalidade. In: DIONÍSIO, A. P.; MACHADO, A. R.; BEZERRA, M. A. (Org.). Gêneros textuais e ensino. 4. ed. Rio de Janeiro: Lucerna, 2005.p.19-36.

MANTOAN, M. T. E. et al. Pensando e fazendo educação de qualidade. São Paulo: Moderna, 2001.

OLIVEIRA E PAIVA, Vera Lúcia Menezes de. Gêneros da linguagem na perspectiva da complexidade. Linguagem em (Dis)curso - LemD, Tubarão, SC, v. 19, n. 1, p. 67-85, jan./abr. 2019.

STREET, Brian V. Letramentos sociais: abordagens críticas do letramento no desenvolvimento, na etnografia e na educação. São Paulo: Parábola, 2014.

Recebido em: 31/03/2021.

Aprovado em: 26/06/2021. 